\title{
LA NOCIÓN DE PROVIDENCIA SEGÚN SAN JUSTINO
}

\author{
DAVID TORRIJOS CASTRILLEJO \\ Universidad San Dámaso \\ dtorrijos@sandamaso.es
}

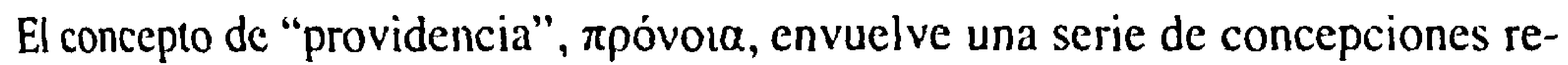
ligiosas presentes no sólo en el mundo griego y en el hebreo sino también en otras muchas tradiciones. Sin embargo, el término como tal adquiere esta significación gracias a su examen específicamente filosófico, que desarrolla varios aspectos especulativos de gran riqueza, relacionados con la causalidad, la necesidad y la contingencia, la estructura de la acción humana, así como el libre albedrío.

Al nacer el cristianismo, se encuentra con una amplia reflexión acerca de esta problemática que había sido emprendida por los grandes filósofos griegos clásicos y fue después desarrollada por las distintas escuelas helenísticas, las cuales se concentraron especificamente en este tema. Por otro lado, existen reflexiones de cuño hebreo que se centran más agudamente en él, como el libro de $J o b$, e incluso el término $\pi$ póvola es aplicado a Dios por Sabiduría': ambos libros pasarán a formar parte del canon cristiano de las Escrituras. Además, disponemos de un desarrollo judaico decididamente filosófico como el de Filón. Por lo demás, en el Nuevo Teslamento no encontramos una atención a la temática de la providencia desde un punto de vista filosófico, aunque se hable continuamente de un Dios providente ${ }^{2}$. En esta misma línea se desenvuelve la litcratura de los así llamados "Padres apostólicos", pero entre sus páginas hallamos ya las primeras menciones del término

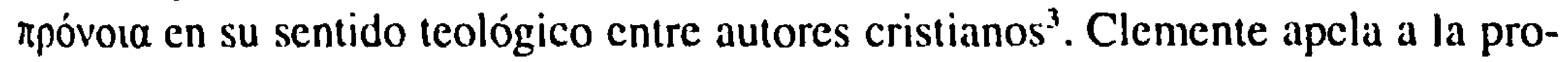
videncia divina que ha determinado resucitar a los muertos al final de los tiempos (l Clem., 24, 5), del mismo modo como hace brotar las plantas de las semillas una vez desechas, en clara alusión a ciertos pasajes del Nuevo Testamento (cf. I Cor $15,42-44 ;$ Jn 12, 24-25). Por su parte, Hermas aplica la palabra a la fundación de la Iglesiat. En estos pasajes, sin embargo, esos autores cristianos no parecen tener en cuenta las reflexiones filosóficas sobre esta cuestión y, de hecho, omiten el contexto en que primordialmente se ha utilizado, a saber, la disposición y el go-

\footnotetext{
'

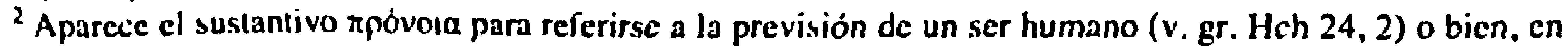
el mismo sentido, el verbo npovotw (v. gr. Rom 12, 17, 2 Cor 8, 21, elc.).

${ }^{3}$ Cr. Simonin 1936, col. 942.

+
} 
bierno divino del cosmos. La sabiduría y el poder divinos empleados en la creación del mundo - atendida con otros términos-, sostendrían también los hechos históricos cruciales para los cristianos.

Serán los así llamados "Padres apologetas" quienes tendrán en cuenta esta noción no sólo como un contenido implícito en la doctrina de Moisés y de Jesucristo, sino como una idea a la que habrían aludido más o menos felizmente los filósofos. En efecto, entre ellos tal idea «se desarrolla tan positiva como abundantemente en antítesis al fatalismo y a la fe en los demonios $»^{5}$. La noción de providencia, como veremos, adquirirá un considerable protagonismo entre estos autores eclesiásticos que se valdrán de ella como un concepto transversal con el cual interpretar buena parte de su teología. Es, pues, inexacta la tesis de Elliott, quien, en su reciente estudio histórico sobre esta noción, ha afirmado que «en las primeras décadas de la historia de la Iglesia parece haber habido pocos intentos efectivos de afrontar el tema de la Providencia; los apologetas tan sólo lo habrían tocado al afirmar que Dios sostiene el mundo mediante la Pax Romana» ${ }^{6}$. Según este autor, san Justino se habría limitado a referirse a una providencia atingente únicamente a los creyentes y sólo Atenágoras habría atendido al asunto con mayor cuidado. Sin embargo, como veremos, es precisamente Justino quien abre la discusión acerca de esta cuestión en ámbito cristiano y lo hace con ricas reflexiones que merecen peculiar atención. A él en particular nos dedicaremos en estas páginas.

Después de Justino encontraremos una continuación ulterior de sus pensamientos entre otros de los primeros apologetas como Taciano, Atenágoras y Teófilo de Antioquía, cuyo máximo desarrollo será alcanzado más tarde por Clemente de Alejandría, Orígenes, etc. Por otra parte, algunos de los primeros apologetas han omitido estudiar el tema de la providencia, al menos en las obras conservadas. Así, Arístides, pese a referirse, al inicio de su Apología ${ }^{7}$, a la providencia divina para hablar de su propio nacimiento, no estudia la problemática bajo el punto de vista adoptado por las distintas escuelas filosóficas. Del mismo modo, Hermias, quien despacha a buen número de filósofos griegos, tampoco atiende a su comprensión de la providencia.

\footnotetext{
${ }^{5}$ Scheffczyk 1974, 36 .

- Elliot 2015, 8: «In the earliest decades of the history of the Church there seems to have been little real attempt 10 address the issue of Providence; the Apologists only touch on it when claiming that God's sustains the world through the Pax Romana, while some contemporaries were convinced the world was at an end, so that to speak of God's providence of it would have been a futile pursuit. Justin Martyr saw biblical, interventionist providence as concerned with the souls of believing individuals only [.... . Compared with the other second-century Apologists for whom Creation and its initial goodness, was more of a concern, Athenagoras had quite a lot to say on Providence as God's ongoing ordering activity in creatiol" and human free will. He was possibly the first Christian to distinguish "general" from "specific" providence».

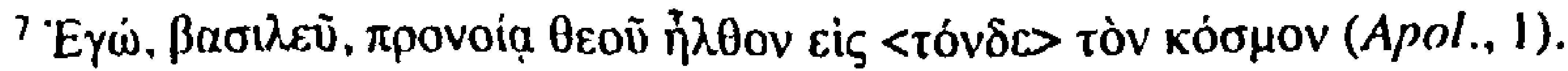




\section{Relevancia de la cuestión DE La PROVIDENCIA.}

En su Diálogo con Trifón, Justino comienza recomendando a su interlocutor judío las doctrinas recogidas por Moisés que aventajarían en mucho a las de los filósofos, pues la mayoría de ellos «ni se plantean siquiera el problema de si hay un solo Dios o hay muchos, ni si tienen o no providencia de cada uno de noso"ros ${ }^{8}$. Según algunos de ellos, esta consideración no aportaría nada a nuestra felicidad; en esto reconocemos las tesis características del epicurcísmo, pues Epicuro créa que ésta se alcanzaría mejor si la divinidad nos ignoraba que si supiera algo de nosotros?.

Al punto, Justino se refiere a otra postura que admitiría, sí, la providencia, pero tan sólo de modo general, sin reparar en los individuos: «Es más, intentan persuadimos que si del universo en general y hasta de los géneros y especies se cuida Dios. pero ya no ni de mí, ni de ti, ni de las cosas particulares; pues de cuidarse, no lc estaríamos suplicando día y noche» ${ }^{10}$. Esto parece aproximarse a una doctrina que suele adscribirse a Aristóteles, pues se podría deducir de una obra atribuida a él, el tratado Sobre el mundo": Dios se ocuparía tan sólo de las cosas celestes y sus movimientos, los cuales provocarían los cambios en el mundo sublunar. De este modo, podría deducirse que Dios conocería las especies producidas por este movimiento, pero no los individuos. Sin embargo, el tratado Sobre el mundo no llega expresamente a esa conclusión; hay que encontrarla más bien en fuentes medioplatónicas $^{12}$. Sin embargo, será un medioplatónico como Ático

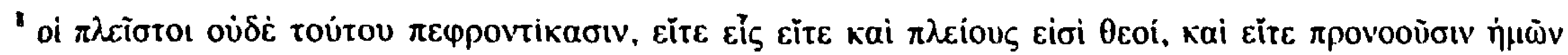
éxáotov cirte kai oú (Dial.. 1,4). Tomo la traducción de Daniel Ruiz Bueno 2002, pero la modifico un poco para evilar algunas añadıduras semánticas que el autor, con ánımo de interpretar, se permite; para el lexto griego de las obriss de Justino, sigo la edición de Goodspeed 1915.

${ }^{9}$ Cf. v. gr. D. L. 10, 123-124, 133-134; Cic., ND. 1, 20, 56.

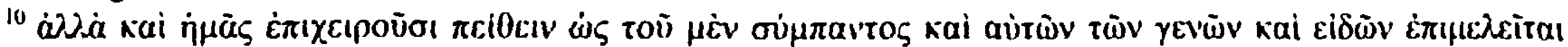

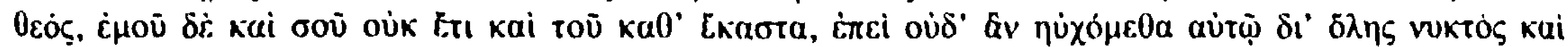

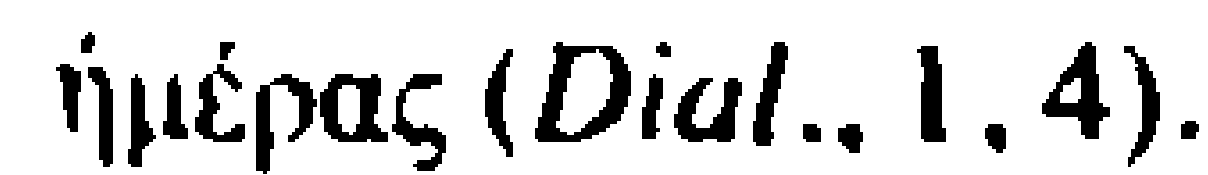

"Cr. Festugière 1981, 226-228. Véisc De mundo, 397 b $30-398$ b 35 . El tratado dice que Dios dispone las cosas celestes y sólo afecta al mundo sublunar a través suyo. A partir de ahí y fundándose en ciera teoría del conocimiento (seguramente pasada por Platón: cf. Parm., 134c-e), se hal debido de deducir que Dios sólo conocería lo general pero no los particulares. Ahora bien, el De mumdo habla expresamente de

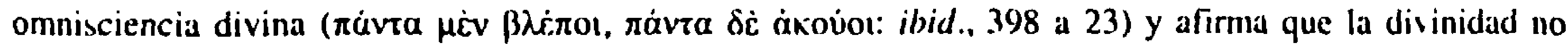
necesita usar de los cielos para obrar en el mundo sublunar; si lo hace es para realzar su majestad (ibid., 398 b 10-16). No está dicho, pues, ni que Dios ignore el mundo sublunar, ni que éste se halle abandonado por la providencia divina - sino todo lo contrario-, si bien se nos antoja más desordenado que cl supralunar (ibid., 397 b 30 - 398 a 1) como ya afirmaba Aristóteles mismo (Metciph., $\Lambda, 10,1075$ a 19-23). Sin embargo, tanto Diógenes Laercio como Aecio atestiguan que la providencia divina "para Aristóteles" se extendería tan sólo al cielo (pero ni siquiera ellos se refieren a la distinción entre cl conocimiento de las

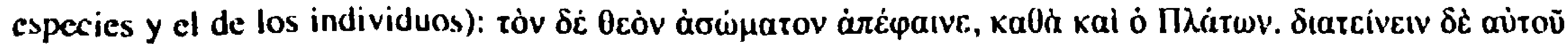

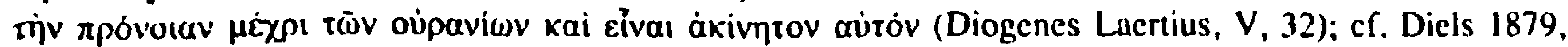
330. Sin duda, la restricción de la providencia divina hasta la esfera de la luna ya se habri convertido en la época de Justino en una tesis comúnmente defendida entre los peripatéticos: cf. Fazzo 1999, 24.

${ }^{12}$ Sharples 1983a. 150)-151 cree que la idea de una providencia que tan sólo se ocupa de lo general pero no de los particulares no es estoica, como se ha dicho alguna vez, sino medioplatónica. En efecto, encontramos la negación de la atención a lo particular y la consideración sólo de lo general en esta fuente mediopla- 
- contemporáneo de Justino - quien atribuirá a Aristóteles esta tesis con mayor resolución: sin hacer mención de la distinción técnica entre el conocimiento de especies y el de los particulares, niega expresamente que la divinidad aristotélica se ocupe de los individuos humanos y ni tan siquiera de los héroes ${ }^{13}$. La noticia de Ático entraña especial interés porque vincula estrechamente el pensamiento de Aristóteles con el de Epicuro a este respecto, tal como vemos hacer a Justino en nuestro texto. Sea como fuere, parece que los peripatéticos acabaron compartiendo un punto de vista muy próximo a este. Vemos así a Alejandro de Afrodisia extender la providencia tan sólo a las especies ${ }^{14}$; además, seguramente, apoyándose en esta idea, algunos peripatéticos negaron incluso la eficacia de la oración, como se recuerda también en nuestro pasaje ${ }^{15}$. Por esta razón, Taciano, discípulo de Justino, atribuye a Aristóteles una visión estrecha de la providencia ${ }^{16}$.

En tan pocas líneas, Justino ha esbozado dos de los sistemas filosóficos que entrarian en contradicción con el cristianismo. Por una parte, los epicúreos habrian eliminado toda providencia de los dioses para liberar al ser humano y dejarlo en

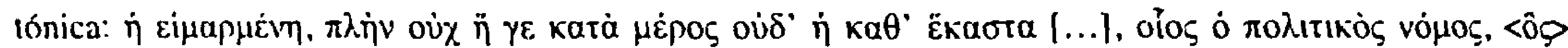

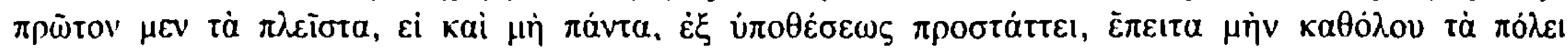

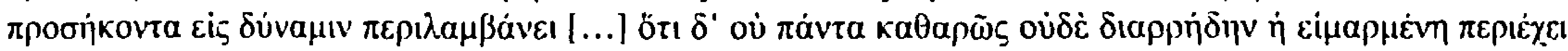

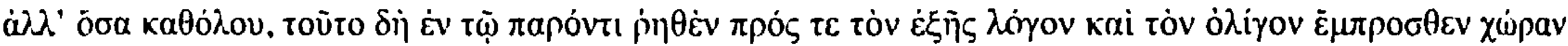

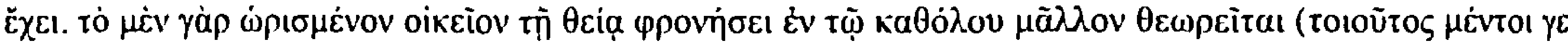

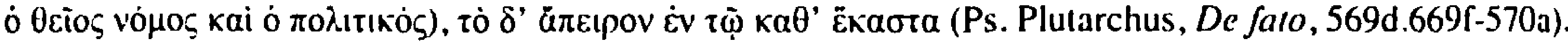
Es más, Epícteto, al enumerar hasta cinco tesis sobre la providencia, distingue entre la postura aristotélica (providencia lımitada al mundo supralunar) y la providencia que no atiende a los individuos: tpito $\delta$ ' oi

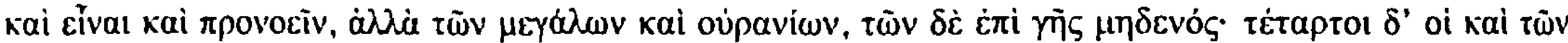

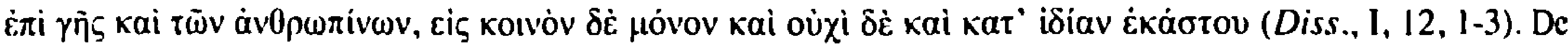
todas formas. no está claro cuál sea la "tesis estoica estándar" pues parece que Crisipo creía que ciertos detalles se escapaban a la providencia: cf. SVF II, $1178-1180$.

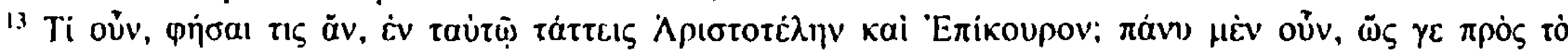

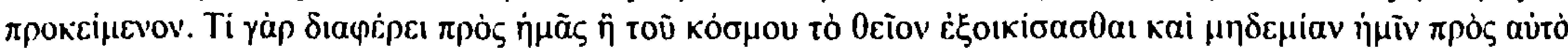

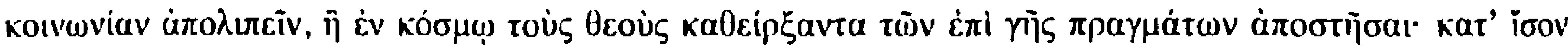

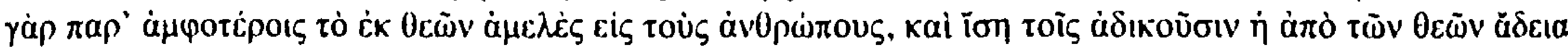

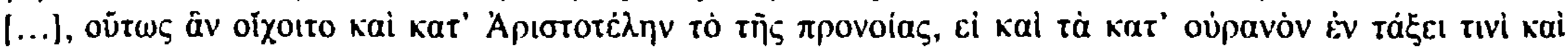

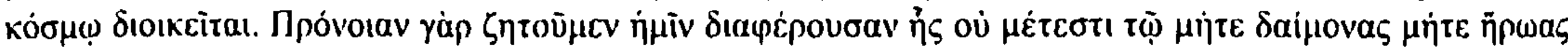

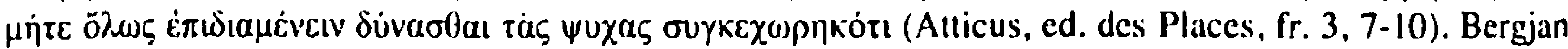
ha mostrado que la argumentación de Justino es idéntica a la de Ático, pues ambos identifican la postura aristotélica con la cpicúrea debido a sus deletéreos efectos para la moral: cf. Bergjan 2002, 227-231.

it En De fato, 25 habla de la conservación de las cosas sublunares pero no se refiere expresamente a las "especies". Sin embargo sí se expresó así en su tratado De providentia, cuyo original griego está perdido y sólo tenemos fragmentos, aunque disponemos de su traducción árabe: cf. Ruland 1976. Se puede consultar más fácilmente en la traducción de Mauro Zonta, elaborada a partir de la de Ruland: cf. Alejandro de Afrodisia, ed. Fazzo 1999; sobre la negación del alcance de la providencia hasta los individuos, véanse las pp. 109.117.125.143 (De prov., 13-25.31.65.89), mientras que en la p. 139 (De prov., 59) se afirma que la providencia tan sólo llega hasta la esfera de la luna, aunque sus efectos se sientan bajo clla. Asimismo. cabe tener en cuenta las noticias sobre esta obra proporcionadas por Maimónides, trad. Fricdländer 2002. 281-282; cf. Sharples 1983b, 25-26. También aparece esta idea, aunque algo más vagamente, en su tratado De principiis, cf. Genequand 2001, $91-93$.

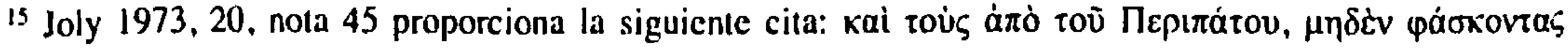

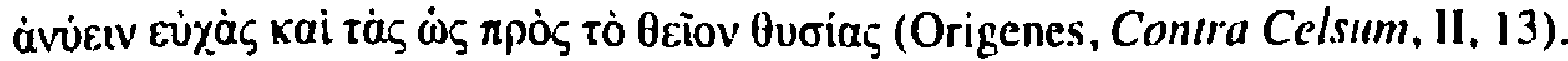

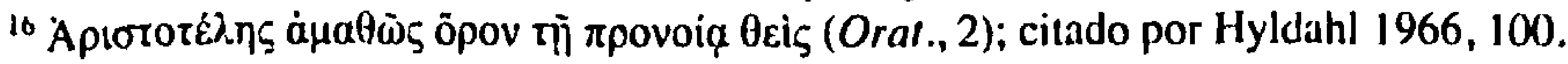


manos de su libre allbedríc. Peor stra parte, les peripateticess habrian hablado de una providencia pero su influcncia se limitaría al cielo y, a través de él. a las especies de los contes sublunares salvaguardadas por su movimiento circulár. Algo semejanic habrian alirmado los medioplatonicos, confiando la providencia de las cosas sublunares a dioses intermedios. Faltaría una cuara tesis helenística, justamente la de aquellos que más relieve habían dado a la providencia en filosofía: la de los cstoicos, los cuales habrían ampliado el alcance de la providencia o hado hasta tal punto que, ocupándose ćsta incluso del más mínimo de los acontecimientos, habría sometido todo el cosmos a su poder. Aunque los estoicos habrían hablado de la libertad de arbitrio, todos sus oponentes verían una contradicción en ello con su doctrina de la providencia. Los cristianos, siguiendo las Escrituras, estarán de acuerdo con ellos en que la providencia se extiende hasta el más mínimo detalle del mundo humano, pues Jesús dijo que Dios se ocupaba no sólo de cada pajarillo sino hasta del último cabello de la cabeza (Mt 10, 29-30). Sin embargo, la insistencia en la libertad personal será mucho más grande que en el estoicismo y, desde lucgo, se extenderá a más posibilidades que al mero dejarse arrastrar por el destino.

Justino arremete a renglón seguido (Dial., 1, 5) contra la postura peripatética, la cual se encuentra en cierto término medio entre el estoicismo y el epicureísmo, pues con el primero admitiría la providencia pero, con el segundo, negaría que ésta se interesase por los sucesos sublunares. Por este motivo, Justino engloba la teoría peripatética con la epicúrea, acusando a ambas de promover la inmoralidad. Según él, el objetivo de estas doctrinas es permitir a cada uno hacer lo que le plazca sin preocuparse del juicio de la divinidad. Que se lee el peripatetismo a la luz del epicureísmo podría demostrarlo la referencia a la doctrina epicúrea del "eterno relorno" contenida en estas palabras: «¿Cómo, en efecto, lo esperan quienes afirman que yo y tú hemos de volver a vivir vida igual a la presente, sin que nos hayamos hecho ni mejores ni peores?»17. Sin embargo, ahí también podría estarse rememorando la doctrina del eterno retorno de los estoicos, a la cual se refiere en otra parte (Apol., 20, 2); además, su discípulo Taciano la presenta exactamente de esa manera (Orat., 3) y, en otro lugar, Justino mismo declara que sus teorías físicas llevan al relativismo moral (II Apol., 6 [7], 8-9). Por fin, Justino reprocha a los platónicos haber hecho el alma de suyo inmortal, por ser incorpórea; pero entonces también sería impasible y no podría sufrir condenas tras la muerte (Dial., 1, 5). Justino, en cambio, cree que el alma es inmortal sólo gracias a Dios ${ }^{18}$.

En este pasaje del Diálogo con Trifón hemos visto cuál es el marco de la providencia: nos permite enlazar en un solo concepto la condición creadora de Dios con sus disposiciones históricas ordenadas en último término a la salvación de cada ser

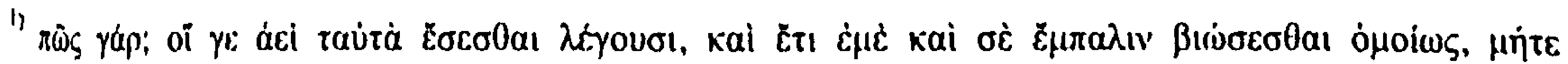

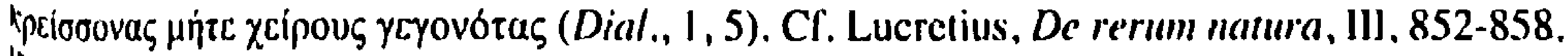

"Cr. Dial., 5, 4-6, 2; Apol., 10, 3; 21, 6. Más claramente todavía lo expresa su discípulo Taciano (Orat., 13). Véase léclix 2010, 1-9.
} 
humano. Por este motivo, es una noción de gran importancia metafísica para encarar el dogma cristiano. Además, advertimos ya algunos de los rasgos más característicos de la presentación cristiana de la providencia, a saber, la aplicación de esta noción al obrar de Dios en la historia, una acción que puede ser correspondida o no por los hombres. De este modo, la influencia de Dios en la naturaleza asi como la conducta ética humana quedan englobadas en un cuadro de mayor envergadura que el empleado por los filósofos anteriores.

\section{LA PROVIDENCIA Y LA CREACIÓN.}

En su Apología, Justino se centra más extensamente en la cuestión de la providencia divina. Denomina a Dios "padre y artífice del universo" ${ }^{19}$, de acuerdo con Platón ${ }^{20}$. El motivo por el cual ha creado el mundo lo toma Justino de la tradición eclesiástica: «[S]e nos ha enseñado que Él, al principio, por ser bueno, fabricó todas las cosas de una materia informe por causa de los hombres» ${ }^{21}$. Podríamos pensar que se están combinando aquí ideas platónicas (Dios como Bien y como Benefactor) con la tesis estoica de la providencia que actúa por mor del hombre. Sin embargo, la referencia de Justino a la catequesis cristiana nos obliga a remitirnos sobre todo a las Escrituras ${ }^{22}$, con las cuales - según él - coincidirían Platón y cuantos filósofos hayan dicho algo acertado (v. gr. Apol., 20,4). Por este motivo, puede afirmar que Dios ha creado todas las cosas no «al azar, sino por causa del género humano ${ }^{23}$, aproximándose bastante a las tesis estoicas. La providencia actuaría por un propósito concreto, a saber, beneficiar al hombre. No cabe duda, este relativo "antropocentrismo" está igualmente presente en el relato del Génesis $^{24}$.

Una parte significativa de la defensa de los cristianos se cifra en señalar su honestidad moral y su consiguiente utilidad pública. Según Justino, los cristianos son los mejores ciudadanos que cabría esperar porque sus doctrinas incluyen la fe en un Dios remunerador cuyo conocimiento se extiende a todas las acciones humanas, incluso en sus detalles más ínfimos y hasta las mismas intenciones del cora$z_{\text {zón }}^{25}$. Aunque el velar de la divinidad sobre los asuntos humanos como garante de

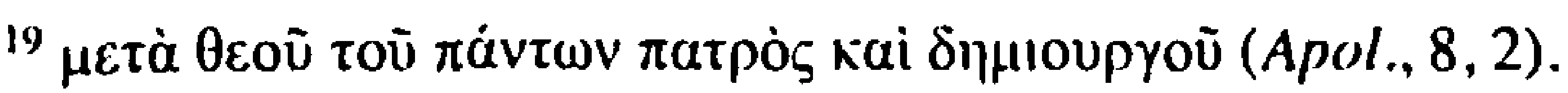

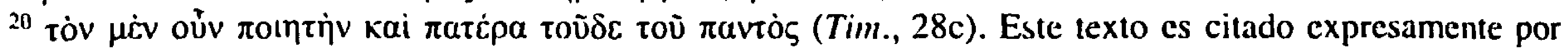
Justino en // Apol., 10, 6, donde en cambio vierte el texto tal como lo hace aquí: Tòv $\delta \dot{\varepsilon} \pi \alpha \tau \dot{\rho} \rho \alpha$ kai

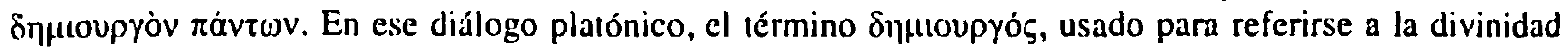

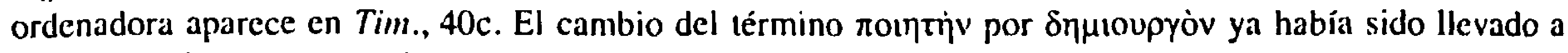
cabo en la cita de este pasaje entre los medioplatónicos: cf. Félix 2013, 95 y nota 23.

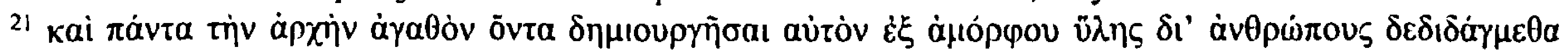
(Apol., 10, 2; cf. II Apol., 4 [5], 2).

${ }^{22} \mathrm{Cf}$. Gn 1, 1-2.26-31; Sal 135 [136], 5-9; 144 [145], 9.

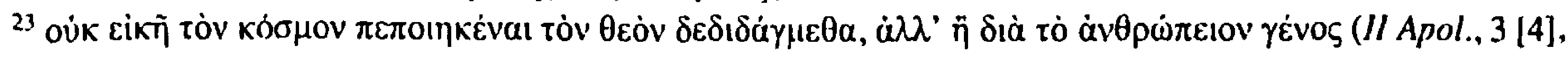
2).

${ }^{24}$ Sobre el hombre como motivo de la creación, cf. Ayán Calvo 1988, 62-63.

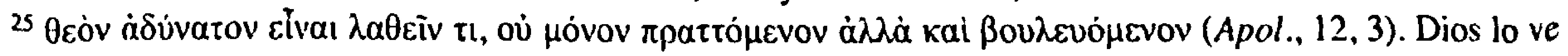
todo: cf. Dial., 127, 2.
} 
justicia era una idea repetida en la literatura gricga así como en la Escritura, será jesús quien, de modo más característico, insistirá en que Dios conoce incluso los pensamientos del corazón ${ }^{26}$. Sin duda, también esta idca ya tenía precedentes en otros textos bíblicos anteriores ${ }^{27}$.

La acción retributiva de Dios está íntimamente ligada a la índole específica que na querido otorgarle al ser humano. Precisamente por haber creado al hombre tal como lo ha hecho, no le castiga inmediatamente después de sus malas obras, puesto que es capaz de arrepentirse (Apol., 28, 2). En lo que sigue, se inspira en las palabras de Pablo, el cual reconoce a todos los seres humanos, incluso aquellos desprovistos de la instrucción recibida de la Palabra de Dios (los paganos), la capacidad de conocer a Dios (Rom 1, 19) y de saber cómo se debe obrar (Rom 2, 15), de modo que ningún hombre tiene excusa ante Dios (Rom 1,$20 ; 2,1)^{28}$. Por este motivo, el Apóstol invitaba a todos a la penitencia. Igualmente, Justino, que acaba de recomendar la penitencia, al punto formula filosóficamente el fundamento que la hace posible: "[A]l principio, hizo Él al género humano inteligente y capaz de escoger la verdad y obrar el bien, de suerte que no hay hombre que tenga excusa delante de Dios, como quiera que todos han sido creados racionales y capaces de contemplar la verdad ${ }^{29}$. Es la racionalidad humana, esa participación en el Logos divino, aquello en que se apoya el reconocimiento de la verdad sobre Dios y sobre la recta conducta al cual se refería Pablo. En ese momento, Justino afronta de nuevo la tesis epicúrea e incluso lo hace recordando la célebre alternativa de Epicuro: "Y si alguno no cree que Dios se cuide de estas cosas, una de dos, o tendrá que confesar artificiosamente que no existe o que, existiendo, se complace en la maldad o permanece insensible como una piedra $)^{30}$. Esta última posibilidad, esto es, la quietud de Dios, constituye justamente la tesis de Epicuro ${ }^{31}$; pero entonces, a los ojos de Justino, el bien y el mal se disolverían y no serían sino opi-

\footnotetext{
${ }^{*}$ Cf. Mt 5, 28 (citado por Justino, Apol., 15, 1; lo comenta en 15, 5 de este modo: ov̀ yà $\rho$ póvov ó

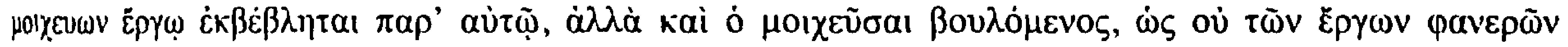

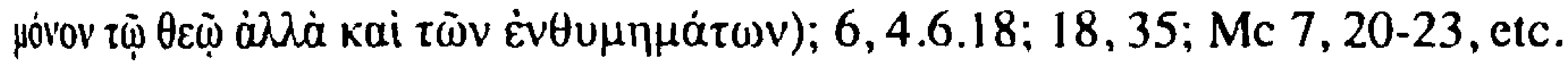

${ }^{n} \mathrm{Cf}$. is 66, 18; Jer 11, 20; I Cro 28, 9; Prov 16, 2; Eclo 35, 22; Sab 1, 3-5; 3, 10; 6, 3; Sal 93 [94], 11; 138 [139], 2.

${ }^{3}$ Me he ocupado de estos dos capítulos de san Pablo en mi trabajo Torrijos-Castrillejo 2016.

"

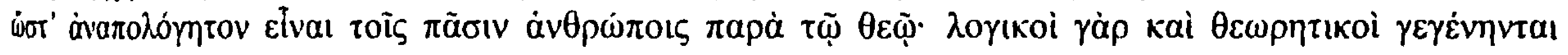
(Apol., 28, 3). Cf. Dial., 93, 1-2.

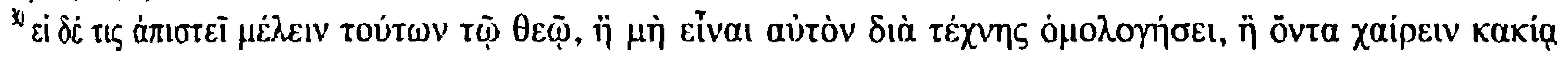

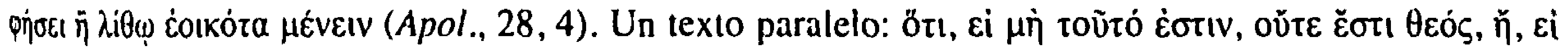

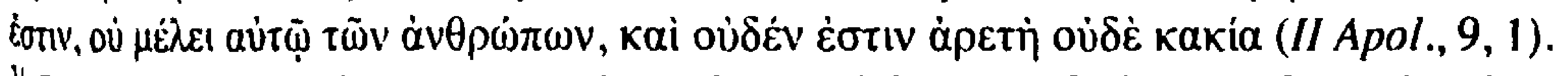

"En efecto, Lactancio nos transmite así la noticia sobre Epicuro: «Deus, inquit Epicurus, nihil curat; nullam igitur habet potestatem. Curare enim necesse est eum, qui habet potestatem; vel si habet, et non Witur, quac tanta causa est, ut ei, non dicam nostrum genus, sed etiam mundus ipse sit vilis? Ideo, inquit, incorruptus est ac beatus, quia semper quietus" (De ira Dei, 17, PL 7, 126-127; cf. Epicurus, ed. Usener, fr. 360). La inercia de la divinidad habría motivado la comparación con la piedra. Por otra parte, también Lactancio deduce que negar la providencia como hace Epicuro equivale a negar la existencia de Dios loCum igitur providentiam sustulit, etiam Deum negavit esse»: ibíd., 9, PL 7, 99).
} 
niones subjetivas ${ }^{32}$. La condena de la insensibilidad del dios epicúreo supone que la bondad y la maldad morales deben tener una intrínseca resonancia de aprobación o desaprobación a los ojos de Dios. Justino no quiere decir que lo bueno y lo malo scan tan sólo, respectivamente, aquello que Dios mande o prohíba; sino que nuestro autor supone un mundo creado por Dios en el cual lo bueno equivale a lo correspondiente a la naturaleza de cada cosa hecha por Él y lo malo a lo disconveniente para ella; además, supone que a cada sujeto humano le ha dado la capacidad para discriminar entre ambos (Dial., 93, 1). Por este motivo, el bien se verifica cuando se vive según la razón, de acuerdo con el logos (el cual participa del Lo-

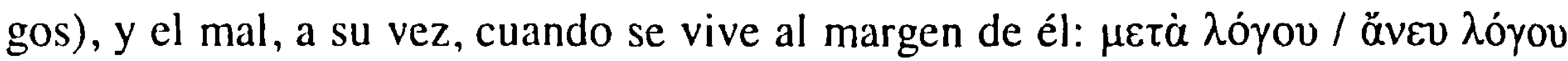

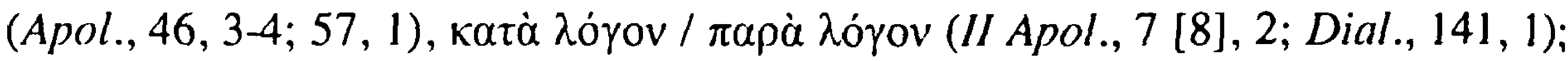
por eso puede explicar la bondad o maldad morales como "imitación" de Dios o separación de Él respectivamente (II Apol., 3 [4], 2). Así, cuando el cristiano se bautiza, pasa de ser hijo de la necesidad y la ignorancia a disfrutar de la libertad y del conocimiento ${ }^{33}$. He aquí el concepto de la "verdadera libertad" característico de la literatura cristiana (Gal 5, 1; Jn 8,33; 9, 32, etc.) ${ }^{34}$. Ya se comienza a mostrar con toda evidencia que. para Justino, cuanto más intervenga la providencia divina en el ser humano, más gana éste en libertad y no al contrario, como suelen temer los adversarios de la noción de providencia.

Vemos, pues, por qué no debe pensarse que Justino comprendiese el actuar moral como fruto exclusivo de las meras fuerzas naturales, las cuales proporcionarian al hombre una suficiencia tal que le harían asequible la perfección moral; tan sólo habría que usar de ellas y esperar una retribución. En este sentido se ha expresado Joly, diciendo que Justino estaba por entero separado de la moral mística de Pa$b^{35}$. Por el contrario, Ayán ha demostrado que en el concepto mismo de "semilla" - que es el modo como está presente el logos en el ser humano- se está contando de manera implícita con cierto desarrollo, el cual depende inmediatamente de una intervención directa de Dios y de su gracia en el sujeto ${ }^{36}$.

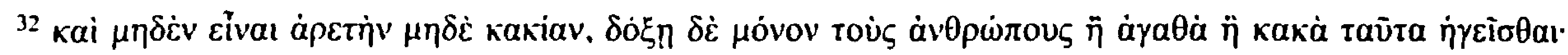
(Apol.. 28, 4). Esta posición acerca del bien y del mal recuerda a estas palabras de Platón referidas a los

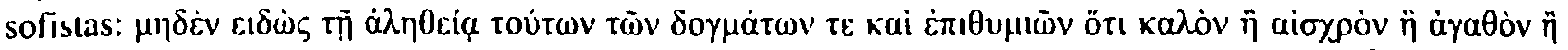

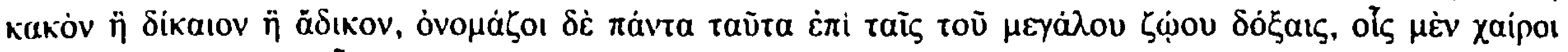

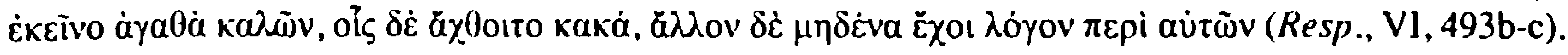

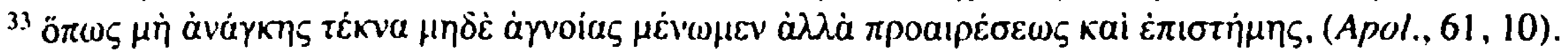

34 Sobre el puesto de Dios, del Logos y del logos humano en la ética de Justino: cf. Merlo 1995, 133-138: 212-230.

35 Joly 1973, 197: “|L]a morale des Apologistes est extrêmement éloignée de la morale paulinienne. Morale du libre arbitre, du préceple et de la rétribution, elle est essentiellement rationnelle et montre comment des penseurs de formation grecque ont réagi très négativement à la mystique morale de certaines formes du christianisme primitif, qui étaient en train cependant de devenir canoniques». Niega más expresamente todavía la intervención de la gracia Magris 2008, 597: "[1]l manicheismo è non meno del cristianesimo patristico una religione della "Legge", non della "grazia". La salvezza è un risultato della libera scelta umana, non della predestinazione divina".

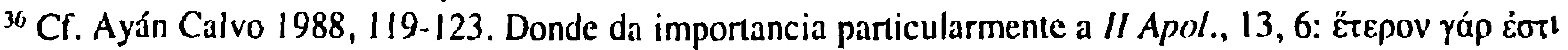

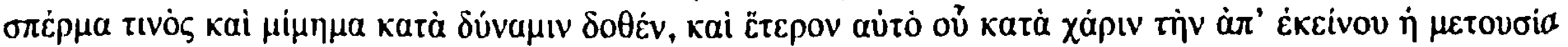




\section{PROVIDENCIA Y LIBERTAD.}

Según Justino, la mejor prueba de la verdad de los hechos sobre los cuales versa la fe cristiana es el cumplimiento en ellos de las profecías (Apol., 30), puesto que es distintivo de una sabiduría divina la capacidad de conocer infaliblemente el futuro (ibíd., 12, 10). Por este motivo, relata los episodios de la vida de Jesús que nabían sido previstos en las Escrituras. En cierto momento esto mismo le da pie para plantearse la cuestión filosófica de la posible contradicción entre la omnisciencia divina, que predice incluso el futuro, con la libertad de arbitrio humana (ibíd., 43). En efecto, entre los paganos la adivinación del futuro también suscitaba este mismo problema ${ }^{37}$. Justino afirma que los acontecimientos son de antemano preconocidos ( $\pi \rho 0 \varepsilon \gamma\left(\omega \sigma \mu \varepsilon^{\prime} \alpha\right)$ por Dios, pero ello no implica que estén determina-

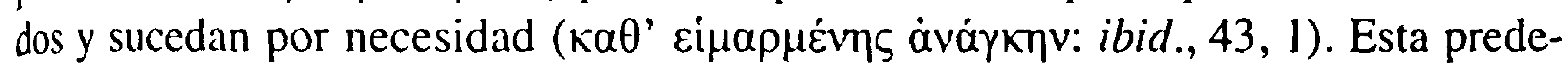
lerminación contradiría el libre albedrío que es un supuesto de la retribución divina. Aunque Justino no discute aquí el sentido que puedan tener las palabras de Pablo sobre la predestinación, está claro que es plenamente consciente de la problemática implicada en este asunto y que su afirmación trata de hacer justicia a la onnisciencia divina no menos que al libre arbitrio humano. Por este motivo, las afirmaciones de Aldo Magris sobre la taciturnidad de los primeros autores eclesiásticos sobre este particular son injustificadas ${ }^{38}$.

Lo más importante de su argumentación es la prueba con que Justino sostiene sus palabras. Según Justino, la doctrina del destino ( $\varepsilon i \mu \alpha \rho \mu \varepsilon \dot{v \eta})$, en la que evidenremente se reconoce la postura de los estoicos, pese a lo que ellos afirman, impedi-

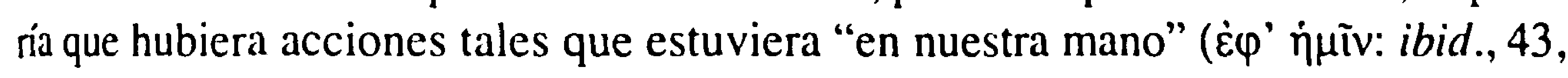
2) llevarlas a cabo o no. Ya Aristóteles había hablado de ciertas acciones que estarían "en nuestra mano" ( $\dot{\varepsilon} \varphi$ ' $\dot{\eta} \mu \mathrm{i} v$ ), frente a todas aquellas que, incluso cuando se producen en nosotros, no somos capaces de determinar en su especie ni en su ejecución por nosotros mismos, como la digestión o la caída de los graves ${ }^{39}$. Por consiguiente, si todas las acciones estuvieran predeterminadas como éstas, entonces, como también afirmaba Aristóteles ${ }^{40}$, no sería posible ni la alabanza ni el vituperio (ibíd., 43, 2.8; cf. II Apol., 6 [7], 6), ni tampoco la legislación, que manda unas

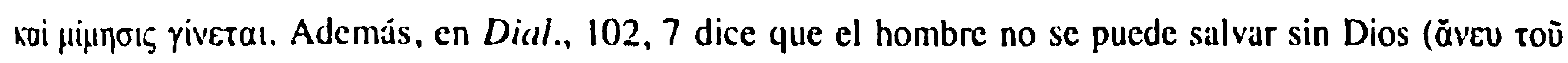
Ocoù) y en ibíd., 110, 3 afirma que la piedad, la fe, la filantropía, la justicia y la esperanza vienen a los

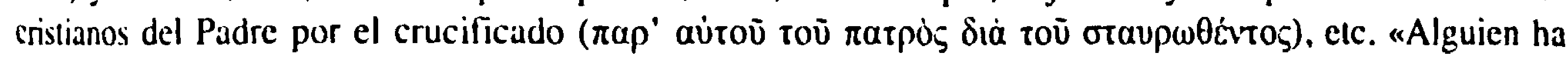
dicho que en el pensamiento del mártir ni el pecado ni la gracia juegan papel alguno. Parece claro que $\mathrm{C}$. Andresen estaba muy lejos de haber accedido a las entrañas de la teología del mártir Justino" (Ayán Calvo, ibid., p. 240).

${ }^{37}$ Cf. v. gr. Cic., $N D, 20,55 ; 65$, etc.

* Según Magris, Justino y los padres alejandrinos habrían abandonado ya el tema de la predestinación planteado por Pablo y además no darían cuenta del sufrimiento del justo: cf. Magris 2008, 590-591.

${ }^{3}$ Cr. E.h. Nic., I1I, 3, 1112 a $21-33$.

${ }^{*}$ Cf. Eth. Eud., II, 6, 1223 a 10-13; Eth. Nic., III, 1, 1109 b 30-35. Esta temática, seguramente por influencia de Caméades, se suele repetir como característica objeción a la negación de la libertad humana: cf. Cic. ND 36,87, elc.; Alcinoos, Didaskalikos, 26... 
cosas y prohíbe otras (II Apol., 6 [7], 7; 9, 1). En efecto, si desapareciese la "libre

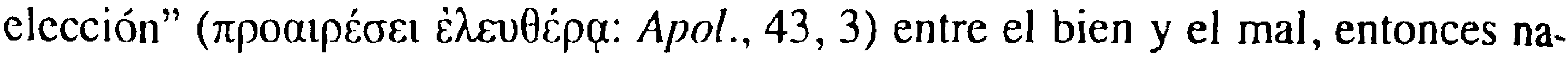
dic sería responsable de sus acciones ${ }^{41}$. En este punto llega la prueba de la existencia de esta libertad de elección de aquellas acciones que están "en nuestra mano":

Vemos que el mismo hombre pasa de un contrario a otro. Ahora bien, si estuviera determinado ser malo o bueno, no sería capaz de cosas contrarias ni cambiaría con tanta frecuencia. En realidad, ni podría decirse que unos son buenos y otros malos, desde el momento que afirmamos que el destino es la causa de los malos porque entonces obra cosas contrarias a sí mismo; o habría que tomar por verdad lo que ya anteriormente insinuamos ${ }^{42}$, a saber, que virtud y maldad son puras opiniones y que sólo por opinión se tiene algo por bueno o por malo. Lo cual, como demuestra la verdadera razón, es el colmo de la impiedad y de la iniquidad ${ }^{43}$.

El razonamiento parte del hecho de la apertura de la acción humana a los contrarios. Era ésta una característica del obrar racional frente a las potencias desprovistas de razón según Aristóteles (Metaph., $\Theta, 2,1046$ b 4-7). Justamente, es propio de lo que está "en nuestra mano" ser de diferentes modos y no de uno solo, lo cual significa que el ser humano puede hacer cosas de diversas índoles pero también que es capaz tanto de lo bueno como de lo malo. Ahora bien, si se afirma, con los estoicos, que todas las acciones humanas están determinadas por el destino, entonces eso significa que a unos los determinaría a obrar bien y a otros a obrar mal. Pero entonces quedaría sin explicar la inconstancia de unos y otros, puesto que, al parecer, Justino cree que los que obran generalmente bien podrían pecar alguna vez y los malos también hacen de vez en cuando alguna obra buena. Esta mudanza en el bien es una interesante característica del punto de vista cristiano, el cual perturba, al menos hasta cierto punto, la estabilidad típica de la virtud grie$\mathrm{ga}^{44}$.

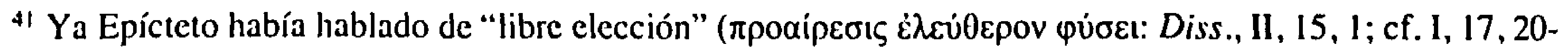
29). En él vio Frede al descubridor de los elementos esenciales del libre arbitrio: cf. Frede 2011, 76-77. Naturalmente, aunque Aristóteles sea el origen remoto de estas nociones, el contexto próximo para comprender a Justino es más bien el mundo estoico, de donde procede otro término para la libertad de arbitrio

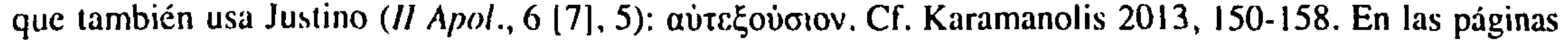
siguientes, Karamanolis señala otros parecidos de la argumentación de Justino con los medioplatónicos y los peripatéticos. En esos razonamientos sobreviven los de Carnéades: cf. Amand de Mendieta 1973, 203 207.

${ }^{42}$ Cf. Apol., $28,4$.

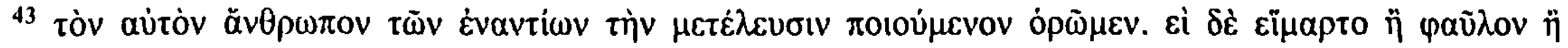

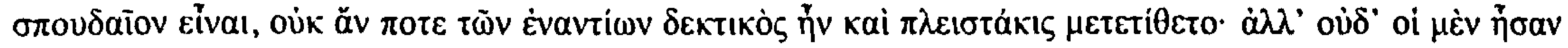

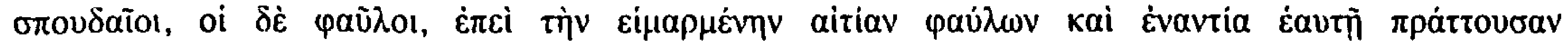

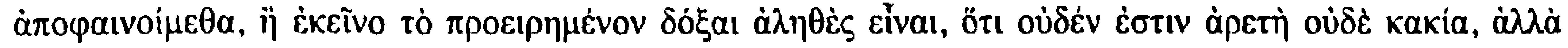

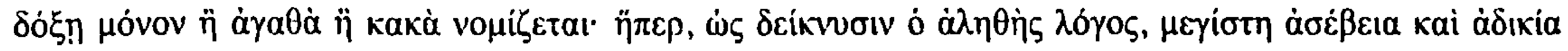
غ̇otiv (Apol., 43, 5-6).

${ }^{44}$ La Escritura afirma expresamente que todos los hombres pecan (1 Re 8, 46; 2 Cro 6, 36; Sal 13 [14], I3 ), incluso los justos (Prov 24, 16), y, como es bien sabido, la universalidad del pecado constituye un importante tema de la predicación de Pablo (Rom 3, 10.23; 5, 12), como antes lo había sido de Jesús (Lc 
La segunda parte del raciocinio proporciona otro argumento a la vez que extrae la consecuencia del anterior. Si el destino es causa tanto de la conducta de los buenos como de la de los malos y la de ambos es inconsecuente, entonces el destino obra de modo contrario a sí mismo. Es una ley inestable y arbitraria. Pero esto es justo lo contrario de lo supuesto en el concepto mismo de destino, a saber, su condición de principio de determinación. El segundo argumento, o, si se prefiere, la segunda variante de esta argumentación, se detiene en las nociones mismas de bien y de mal. Si resulta que el destino es causante tanto de las acciones buenas como de las malas, entonces desde luego no se puede pensar en el destino como en una causa natural, porque, como hemos dicho antes acordándonos de Aristóteles, no es posible que semejante causa desprovista de razón sea capaz de producir diferentes efectos. Puesto que el destino que determina tanto lo bueno como lo malo habría de ser racional, entonces debe seguirse una de las dos consecuencias que ya se habian anunciado antes y fueron indicadas por nosotros: que el destino "sc complacería en la maldad" o bien sería "indiferente como una piedra" tanto respecto del bien como del mal. Si se da la primera, entonces el destino no podría ser considerado una divinidad, ya que se supone que ésta ha de ser buena. Si se da la segunda, entonces todas las acciones serían indiferentes y los nombres de "bien" y "mal" scrían meras convenciones. En la Segunda apología retornará sobre este mismo argumento denunciando con él de modo explícito a los estoicos (II Apol., 6 [7], 8-9; 9, 1). Según cree, se contradicen a sí mismos porque admitirian la calificáción moral de las acciones, pese a hacerla imposible con sus doctrinas físicoicológicas. Al identificar a Dios con el mundo y los elementos, o Dios se volvería

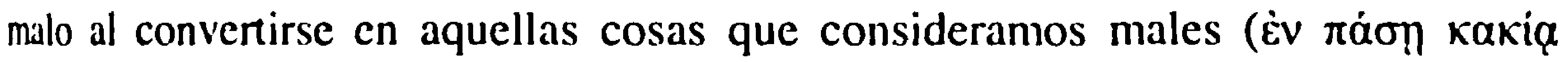
yivónevov), o habría que hablar de una total indiferencia entre el bien y el mal, disolviéndose así la oposición entre ambos.

En definitiva. Justino cree que uno llega a ser bueno o malo por su propia elecsión y es responsable de ello; pero esto no contradice que exista una disposición de Dios que condene a los culpables y premic a los inocentes. En este caso, no

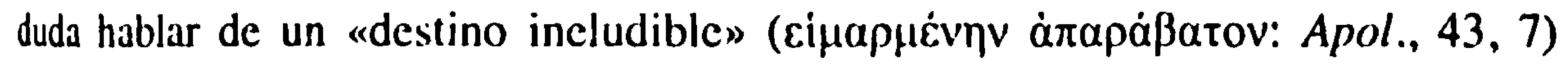
usando la terminología característica de la Estoa. Que las consecuencias de las acciones humanas libres sean inevitables era algo también admitido por los medioplatónicos, como es el caso de Alcínoo, quien afirma que el destino se comporta como una ley, que decreta determinadas implicaciones ante ciertos modos de vida o conductas ${ }^{45}$. Esta concepción se acomoda bien a la Escritura, según la cual Dios ha decretado vida eterna y condenación según las obras de cada uno (ibíd.,

13.4-5; $\mathrm{cf}$. Jn 8. 7). Sobre la imponancia del pecado en el planteamiento de Justino: cf. Ayán Calvo 1988, 38.

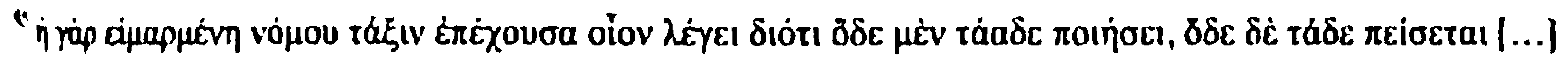

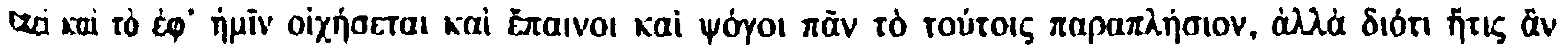

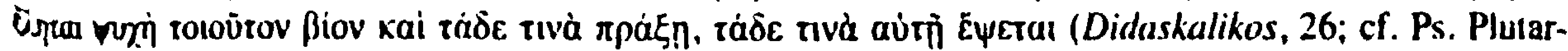
(t). De farn, 569d-570d). 
44, 1-7). Hay dos puntos de semejanza entre el medioplatonismo y la escatología cristiana: que se siguen necesariamente determinadas consccuencias a determinadas acciones y que existe una ley, una disposición divina, que liga estos efectos a estas causas.

Por este motivo, Justino ve en plena continuidad la doctrina bíblica con las enseñanzas de los medioplatónicos, quienes otorgan gran importancia al mito de $\mathrm{Er}$ de la Repíblica de Platón que Justino no duda en citar aquí: «La culpa es de quien elige, Dios no tienc culpa ${ }^{46}$. La condenación de los malvados no es responsabilidad de Dios sino de quien libremente ha obrado mal y este destino escatológico habría sido admitido también por los gricgos (Apol., 20,4). En este punto, Justino justifica la semejanza entre la doctrina mosaica y la platónica con su célebre teoría de los "gérmenes de verdad" ( $\sigma \pi \varepsilon ́ p \mu \alpha \tau \alpha$ à $\lambda 0 \varepsilon i \alpha c$ : ibíd., 44, 9) que se hallarían dispersos entre todos los hombres, incluso los filósofos griegos. Sin embargo, ya que estos gérmenes son participaciones del Logos revelado en Jesucristo, en quien se ha manifestado la verdad plena y ya no parcialmente, todos estos gérmenes podrían ser integrados en el Cristianismo como auténticamente propios suyos (ibíd., 46; II Apol., 10). Por este motivo, quienes antes de Cristo, Logos encarnado, vivicron conforme al Logos, ya tuvieron la oportunidad de ajustarse a los designios divinos que se han cumplido plenamente en la Encarnación. Por lo demás, de acucrdo con una tradición apologética judía que se remonta a Aristóbulo ${ }^{47}$ y después scrá seguida por Filón ${ }^{48}$ y Josefo ${ }^{49}$, Justino afirma que Platón habría aprendido de Moisés cuanto dijo de verdadero (Apol., 44, 8; 59-60). Otras semejanzas cventuales entre las doctrinas de los poetas o de los filósofos se deben a la malicia de los demonios que han propalado entre los griegos remedos falsos del contenido de las profecías de la Escritura (ibid., 5.54-56.62.64. etc.).

Por fin, Justino concluye la sección que venimos comentando (ibid., 44, 11) diciendo que los hombres no están determinados a ser buenos o malos, pero esto no obsta para que cicrtamente haya un decreto divino que destine ineluctablemente a los buenos al premio y a los malos al castigo. Tampoco la libertad se encuentra en

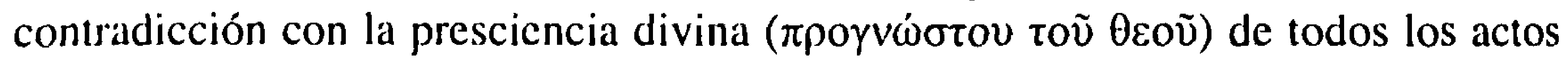
humanos ${ }^{50}$. Esta presciencia se cxpresa en las profecías, las cuales también incluyen el cuidado por la salvación de los hombres, pues exhortan a cambiar de conducla mientras los aludidos estén a tiempo ${ }^{51}$. También esta presciencia es la base de lo que podríamos llamar "predestinación" (Pablo usa no sólo $\pi p o \varepsilon ́ \gamma v \omega$, como Justino, sino también $\pi \rho o o p i \zeta \omega: \operatorname{Rm~8,29-30):~poco~después~se~dice~que~la~escato-~}$

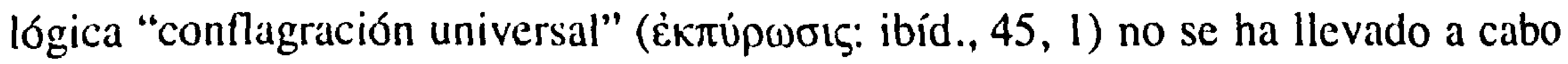

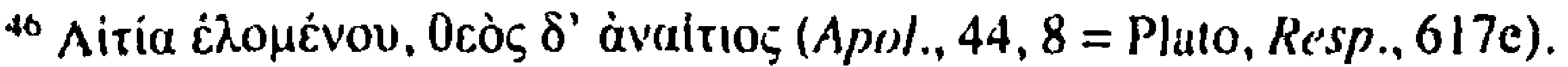

${ }^{47} \mathrm{Cf}$. Eusebius, Praeparatio el angelica, XIII, 12.

${ }^{48} \mathrm{Cr}$. Wollison 1962,141-142.

${ }^{49}$ Cr. Contra Apionem, II, 168-169. Véase Thompson-Wajdenbaum 2014, 5, nota 21.

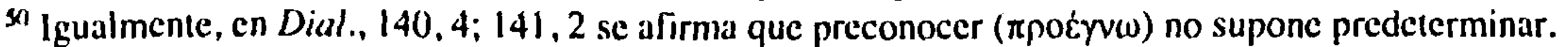

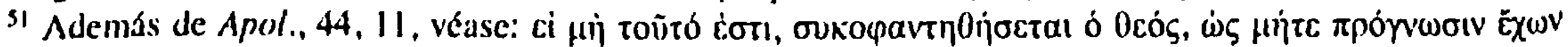

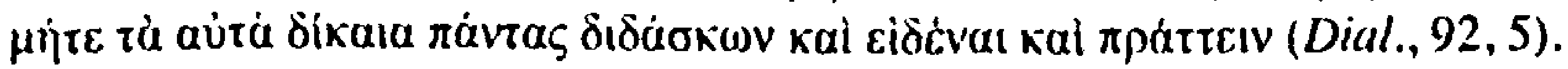


todavia porque aún se debe completar el número de los buenos y virtuosos ${ }^{52}$. Está claro que Justino no ve contradicción alguna entre la certeza cognoscitiva acerca del futuro y su predeterminación, como no la hay de hecho. En realidad, presuponer que el conocimicnto es cierto sólo si su objeto es necesario supone un prejuicio reórico que evidentemente Justino no comparte y ni siquiera se cree en la obligación de combatir, pese a las influyentes tesis de Diodoro Cronos ${ }^{53}$.

\section{4. ÁNGELES Y DEMONIOS, MEDIADORES DE LA PROVIDENCIA.}

Hemos comentado antes que los demonios son responsables de los engaños en que están varados los paganos. Pues bien, acudamos ahora a la Apología segunda para considerar con más detalle el lugar que ocuparían los ángeles en general en el plan de la providencia. Antes de comenzar, se debe recordar aquí el planteamiento de la providencia que sostuvieron los autores medioplatónicos. Por ejemplo, el Pscudo-Plutarco nos indica que habría tres niveles de providencia (De fato, 9): el primero correspondería a Dios, que ha ordenado el resto de las cosas del mejor modo posible, $\mathrm{cl}$ segundo, a los dioses que gobiernan el mundo ccleste, mientras que el tercero sería competencia de los démones que se ocuparían de los asuntos humanos. Como veremos, Justino también hablará de mediadores entre Dios y los hombres, pero esto no impedirá a Dios tener una providencia directa c inmediata de todas las cosas $y$, en particular, del género humano. Si hay tres niveles, más bien habría que hablar del Padre, del Logos y de los ángeles, más una "providencia negativa" de los demonios (la cual no aparece entre los medioplatónicos). Quizá el punto de vista de Justino tenga un paralelismo más próximo con Filón quien, por su parte, introduce a los ángeles como mediadores de la providencia de Dios junto a su Logos ${ }^{4}$. Aclaremos un poco más la mediación de los ángeles y después nos referiremos a la del Logos.

Pues bien, Justino explica que Dios creó el mundo físico en favor de los seres humanos y a ellos les sometió las cosas terrenas; sin embargo, pese a ese sometimiento, la providencia de tales cosas así como la de los hombres mismos fue confiada a los ángeles (/I Apol., 4 [5], 2). Ahora bien, el mismo libre albedrío que es crucial en el plan de Dios respecto de los hombres, también lo es respecto de los ángeles, pues han sido creados asimismo libres y, por consiguiente, susceptibles de ser juzgados por Dios"s. A pesar de las disposiciones de la providencia divina, un

\footnotetext{
"Fata ided del número de los elegudos evtá tomada del libro del Apecalipsis de Juan: Ap 6, 11; 7,3-4. Más adelante retoma el lenta de la dilas ión en la conflagración. explicándola como un efecto de la paciencia de Dias que espera a que de liedu el fruto requerido de la semilla de los cristianos que acaba de ser sembrada en el mundo. cf. II Apol..6 6 [7], 1-2.

"Segun Dindoro. todo to que sucede aconlece necesariamente, puesto que, una vez han sucedido. los hechess no pueden cambiarse por fuerza son como fueton; luego igual de necesarios eran antes de acaecer I en el nxinkento de producirse. cf. Magris 1985 452-478.

" Cr. Wolfson 1962, 372-374: 414 . También Hermas decía que a los ángeles se les había encomendado cuidar de la creación Pasior, vis. III.4.1.

"Cr.ll Apol .6171. 5: Dual .88.5: 102,4;141,1.
} 
hecho histórico capital determina la situación presente de los hombres, afligidos por multitud de males (como la persecución de los cristianos, las confusiones filosóficas y morales de los paganos, etc.): se trata del pecado de ciertos ángeles. De ese mal se derivarán muchos otros y la providencia divina ajustará sus disposiciones al nuevo contexto histórico generado. En esto vemos la peculiaridad de la especulación judeocristiana sobre la providencia divina: aunque se sirve de los parámetros conceptuales generales del mundo griego, la tradición bíblica proporciona un curso histórico de los acontecimientos en los que ya ha intervenido la providencia - en ocasiones, respondiendo a determinadas acciones libres de las criaturas - determinando los hechos subsiguientes; además, anuncia una serie de intervenciones futuras. De tal manera, los sucesos del pasado llevarán a interpretar de una manera especial lo que acaece en el presente e incluso a dar un pronóstico para el futuro. No es que se interpreten hechos históricos a la luz de la intervención providente de la divinidad, cosa ampliamente presente en la literatura griega (pensemos en Heródoto, Jenofonte, etc.); se trata más bien de determinados acontecimientos históricos que rigen la comprensión misma de la acción providente de Dios. He aquí lo característico del pensamiento judeocristiano, donde hechos históricos como la creación, el pecado, la Encarnación o la Parusía estructurarán toda interpretación de ulteriores intervenciones de la providencia.

El príncipe de todos los demonios es, pues, Satanás, la serpiente que pecó al inicio (Dial., 45, 4; 103, 5, etc.), de acuerdo con la misma Escritura y los escritos del Nuevo Testamento, y él, junto con los demás ángeles y hombres que lo siguen, está destinado al fuego eterno $(\mathrm{Apol} ., 28,1)^{56}$. Para hablar del pecado de los ángeles, Justino asume la narración de los acontecimientos presente en los libros de Enoc y de la literatura apocalíptica judía ${ }^{57}$. Por esto, Justino afirma que el pecado de los ángeles consistió en traspasar los límites del orden dispuesto por Dios: copularon con mujeres y engendraron hijos; éstos serían los así llamados demonios (II Apol., 4 [5], 3; cf. Apol., 5, 2). A la luz de esta narración, se volvía fácil explicar los mitos de Zeus cohabitando con mujeres mortales e incluso con Ganimedes y Justino no dudó en hacerlo ${ }^{58}$. Así, de acuerdo con la postura de Pablo y de la Escritura misma ${ }^{59}$, Justino identifica los dioses de los cultos paganos con los demonios caídos, cuyo objeto es engañar al género humano, hundirlo en el vicio y corromperlo, exigiendo, además, para ellos, un culto idólatra; todo esto recibe el nombre de "fornicación" en la tradición profética ${ }^{60}$.

De esta manera, existe una siniestra providencia de los diablos que intervienen en la historia generando distintos males entre los hombres. Pese a ser solapada, la

\footnotetext{
se Cf. Ayán Calvo 1988, 170-183.

${ }^{37}$ Cf. Ayán Calvo, ibid. 183-185; Daniélou 1991, 184; id 2002,414. El relato de Enoc depende del oscuro pasaje de Gn 6. 2 (el misterioso personaje Enoc aparece poco antes, en Gn 5, 18-24).

SB Cf. Apol., 21, 6; of. II Apol., 4|5], 5-6; 14, 2.

${ }^{34}$ Cf. v. gr. Ex 34, 15; Lv 17, 7; Di 32, 17; Sal. 105 [106], 37; I Cor 10, 20.

${ }^{\infty}$ Cf. Os 1. 2; 2-3; 4, 10-14.18; Is 1, 21:54, 6-7; Jer 3, 1.6-12; Ez 16, 15-52; 23. En Dial., 133, I evoca quizá Ez 16, 20 o Jer 7,31; 19,4-5, identificando a Baal con los demonios.
} 
gición diabólica es eficaz e incluso utiliza a los seres humanos para dañar a quieaes sirven a Dios, como a Cristo, a los cristianos o incluso a justos paganos como Sócrates ${ }^{61}$. Sin embargo, incluso la acción diabólica es integrada en los planes de la providencia divina, la cual es capaz de contar con su acción para obtener bienes aun mayores. El designio de Dios es más poderoso que la pseudo-providencia de sus enemigos (Dial., 103,3) y encuentra el modo de vencerlos para que finalmentc se cumpla Su voluntad. El caso más claro en que se aprecia que las insidias diabólicas se vuclven - a pesar suyo - en instrumentos de la providencia divina es la pasión de Cristo ${ }^{62}$.

La cruz es un acto de misericordia de Dios hacia el género humano (Dial., 106, 1). En ese caso, asegura Justino, era voluntad del Padre que Cristo sufriera por lodos para que así todos fueran perdonados; sin embargo, tampoco esta decisión welve inocentes a sus asesinos judíos (ibid., 95, 2-4). Que la pasión de Cristo era voluntad del Padre, lo muestran distintas profecías, entre las que se encuentra el salmo 21 [22], pronunciado por Jesús desde la cruz, buena parte del cual es copiado por Justino (Dial., 98); en este salmo encontramos varias crudas expresiones de sufrimiento humano junto a confesiones sinceras de esperanza en Dios (vv. 1012.20-23). En lo sucesivo, Justino trata de mostrar cómo se han ido cumpliendo las Escrituras en la vida de Cristo, pues Jesús es aquel por el cual la providencia de Dios ha dispuesto destruir a Satanás, los ángeles y sus secuaces humanos e incluso a la muerte misma (Dial., 100,6).

En la pasión de Cristo es donde mejor podemos advertir la interpretación de Justino acerca de la temática del "sufrimiento del justo". Pone en boca de sus inlerloculores la pregunta sobre los designios de Dios, que consiente tales padecimientos (ibid., 102, 3): por ejemplo, ¿no podría haber sido eliminado Herodes para que no persiguiera a Cristo en su infancia? Justino lleva al extremo esta pregunta: ¿acaso no podría haber sido eliminado desde el principio - cuando pecó- el mismísimo Satanás que ha arrastrado a otros a tantos pecados? E incluso, interrogándose con más radicalidad: ¿no podría Dios haber creado directamente el "número de elegidos" (Ap 6,11) que Él pretende tener en el Cielo? Así no hubiera sido menester esperar tanto tiempo hasta que todos vinieran a la vida a lo largo de los siglos y sometidos a tantos avatares. Con tan sucintos trazos, Justino manifiesta el drama de la libertad puesta en acción a lo largo de la historia. Que los hombres y los ángeles alcancen la vida eterna libremente con sus elecciones históricas cons-

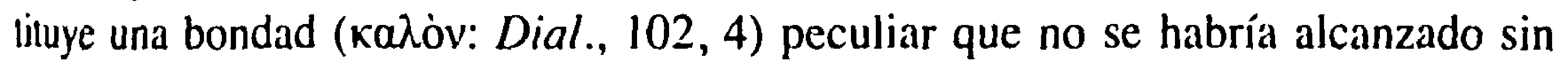
libre albedrí $0^{63}$. Por otra parte, la distensión temporal es una condición para este ejercicio de la libertad que es, por supuesto, dramático. A lo largo de los escritos 


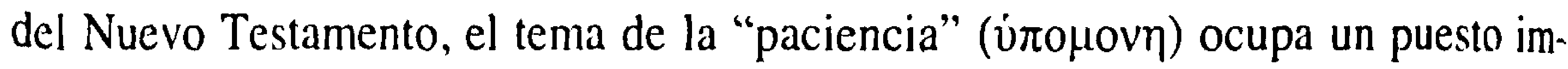
portante, empezando por la misma predicación de Jesús ${ }^{64}$, pero en particular, citemos este pasaje: «Tenéis necesidad de paciencia para cumplir la voluntad de Dios y conseguir así lo prometido» ${ }^{6.5}$. Pablo mismo se había expresado así: "No nos cansemos de hacer el bien; que a su debido tiempo nos vendrá la cosecha si no desfallecemos. Por tanto, mientras tengamos oportunidad, hagamos el bien a todos ${ }^{66}$. La prolongación en el tiempo es un requisito imprescindible para que un ser temporal como el hombre pueda tener la oportunidad de abrazar libremente los designios divinos. Por este motivo, Dios aguarda aún cierto tiempo antes de la conflagración final.

\section{CONCLUSIÓN: EL LOGOS, EL GRAN MEDIADOR DE LA PROVIDENCIA.}

Según Justino, el Logos, procedente del Padre, hecho hombre en Jesucristo, es «el rey más alto, el gobernante más justo que sabemos [...] juntamente Hijo y legado de Dios, Padre y soberano del universo" ${ }^{67}$. El Logos lleva a cabo su gobierno en primer lugar como mediador de la creación de Dios. A través de él, tal como los escritos sapienciales y el corpus paulino habían expresado, es formado el mundo y, en lo sucesivo, todas las cosas son regidas por é ${ }^{68}$.

El Logos ejercita una actividad especial en relación con el conocimiento humano, como hemos visto antes a propósito de la filosofía. Es el responsable de la sabiduría ínsita en todos los hombres, incluso la de los ajenos a la historia salvífica de Israel y la Iglesia. En íntima relación con esta misión, es de señalar la presencia del Espíritu profético ( $\pi \rho 0 \varphi \eta \tau \iota k o ́ v \pi v \varepsilon \tilde{u} \mu \alpha)$ que anuncia estas cosas de antemano, dando a conocer así al Logos; con todo, su pregón resuena también durante la presencia y la acción del Logos en la humanidad de Jesús e incluso acompaña esta acción ${ }^{69}$. El Logos se manifiesta a lo largo de la historia bíblica mediante diferentes apariciones visibles, pero la plenitud de esta manifestación la alcanza al hacerse hombre (Apol., 63, 10.16). En ese momento culmina su misión docente deviniendo así el maestro que «enseñó estas verdades para la transformación y guía del

\footnotetext{
(4 Jesús insiste en que Dios tiene paciencia con su pueblo, "le da tiempo": Lc 13,6-9. También exhorta a sus discípulos a ser pacientes: Lc 21, 19. Igualmente: Rom 2, 7; 5, 3-4; Heb 12, 1; Sant 1, 3-4. etc.

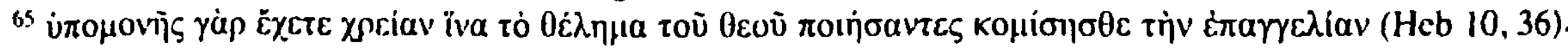
Traducción de Sociedad bíblica de Jerusalén (ed.), Biblia de Jerusalén (Bilbao: Desclée, 2000).

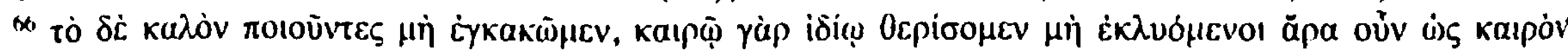

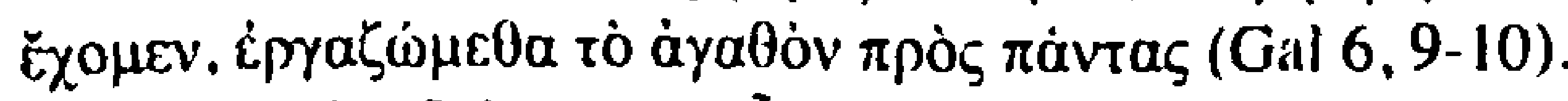

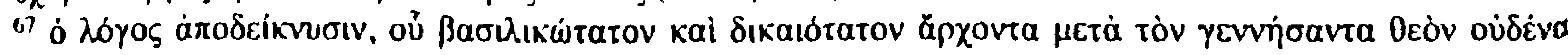

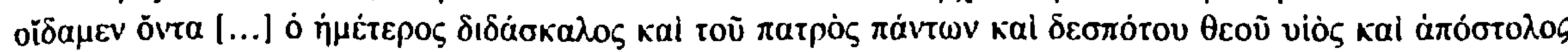
Quv Inбoũ Xplorós (Apol., 12, 7.9).

* Cf. Ayán Cálvo 1988, 52-61.

${ }^{64}$ Cf. Apol., 31, 1; 39, 1; 40, 5; 42, 1-2; 44, 11-12... Dial., 25, 1; 36, 6.. En Apol., 33, 5.9 se dice primero que la profecía viene del Espíritu y luego se atribuye al Logos; por otro lado, en ibíd., 38, 1 el Espíritu habla a través de Cristo. En Dial., 49, 3 el Espíritu precede a la manifestación de Cristo al actuar en los profetas y se dice que esta presencia ( $\pi$ poovola) fue sin gloria (ibid., 49,7).
} 
(énero humano» ${ }^{70}$. Además, por su sacrificio en la cruz, vence definitivamente a la puerte (Apol., 63, 17) y a los demonios que combatían en contra de sus discípulos (Dial., 30, 3; 78, 9). De este modo, se ponía remedio al imperio del mal que se nabía extendido entre los hombres desde el momento en que libremente pecaron por vez primera (ibid., 88,4). Por fin, el Logos hecho hombre, resucitado al tercer día y después subido al cielo, tiene aún reservada una misión para el futuro, cuando vuelva por segunda vez como juez de todos para convertirse en rey perpetuo ${ }^{71}$. En ese momento se hará efectiva la victoria sobre la muerte que ya había sido conquistada por la pasión de Jesús. Mientras tanto, por una especial providencia de Dios, los cristianos prolongan con sus vidas los designios divinos, obrando conforme a Su voluntad y dando el culto a Dios que Él espera del hombre (Dial., 118, 3). En este lapso, como antes vimos, asimismo se va completando el número de los elegidos.

Se aprecian así los rasgos de la providencia tal como la comprende Justino. Retomando su comprensión del Logos, podemos aventurar una interpretación de la idea de providencia sostenida por Justino. Según su presentación, los cristianos serian los depositarios del Logos en su totalidad, mientras que los sabios paganos tan sólo habrían dispuesto del Logos parcialmente. Aunque el Logos sea un ser personal de mayor entidad que el mero conocimiento de fe de los cristianos, no seria descabellado interpretar el contenido del logos perfectamente participado por éstos como un "relato íntegro" frente al "relato parcial" captado por los filósofos paganos, en atención a uno de los significados del término logos. En este sentido, las ideas filosóficas sobre la providencia proporcionarían una faceta verdadera pero parcial de ella, mientras que la visión del asunto alcanzada por la fe sería del todo completa.

Justino puede asumir en este tema una posición filosófica próxima al estoicismo de Epícteto, a la vez que integra algún elemento propio del medioplatonismo, pero la guia conceptual que le permite calibrar entre las distintas posturas es siempre la fe cristiana. Ésta otorga la máxima importancia al poder divino, pero sin reducir un ápice la libertad y la consiguiente responsabilidad humanas. Sea como fuere, este arbitraje entre posturas filosóficas no deja de ser un capítulo de constucción conceptual dentro de un marco mayor proporcionado por la historia de la salvación, la cual constituye - por así decir - el relato completo sobre la providencia. A fin de cuentas, los filósofos paganos elaboraron una comprensión "sincrónica" de la providencia, estableciendo los principios básicos para contar con una divinidad providente en un presente considerado sustancialmente estable. No

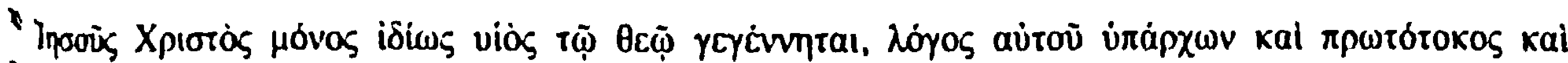

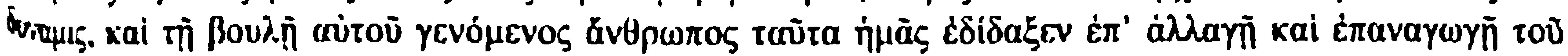
DApuxciou yévous (Apol., 23, 2).

Cr. Dial., 36, $1 ; 40,4 ; 49,2-3 ; 118,1-2 ; 132,1$.
} 
se trataba de una comprensión "ahistórica" como a veces se dice ${ }^{72}$, sino que se limitaba a considerar las condiciones estructurales sobre las cuales se desarrolla la historia. Sin embargo, el pensamiento cristiano, como hemos visto, incorpora determinados acontecimientos históricos del pasado - iy del futuro! - a la explica ción del presente; tales hechos forman parte integral de la explicación, no son meras ejemplificaciones de ella. La intervención de un Dios inteligente, poderoso y bueno en el momento presente no parte de idénticas condiciones en todos los momentos del tiempo sino que ahora nos encontramos en una situación peculiar debido a ciertos acaccimientos del pasado remoto (pecado de los ángeles y de los primeros hombres), lejano (profecía), próximo (Encarnación y Pascua de Cristo), asi como del futuro (Parusía y Juicio). Estos acontecimientos no condicionan sólo coyunturalmente las decisiones de la providencia (esto solía ser admitido en la comprensión tradicional griega, según la cual, por ejemplo, las decisiones de un hombre determinaban el destino de su familia o de su pueblo), sino que constituyen una referencia común a todas las peripecias históricas.

En definitiva, en la teoría de Justino sobre la providencia, empapada de la filosofía de su tiempo, encontramos, por una parte, unas exigencias doctrinales precisas para lo que estamos llamando el marco "sincrónico" de la noción de providencia; por otra parte, vemos un planteamiento novedoso respecto de los filósofos paganos, procedente más bien de la tradición judía, a saber, una presentación “diacrónica" de la providencia. Las condiciones generales en que actúan Dios y el hombre, nos hacen verlos obrar no por separado sino en conjunto; esto sucede en medio de un desarrollo histórico en el que una serie de hechos previos al momento actual establecen ciertas novedades ontológicas determinantes (como el pecado o la gracia) y unas relaciones de justicia precisas que afectan a las decisiones que pueden ser tomadas por ambos. Por este motivo, cerrábamos estas páginas fijándonos en la mediación del Logos, pues en ella apreciamos uno de los rasgos peculiares de la comprensión cristiana de la providencia, la cual entrelazará la acción de Dios con la del hombre ${ }^{73}$. El presunto conflicto entre ambas que desazona a los filósofos paganos ha sido disuelto principalmente por Jesucristo, en quien la voluntad divina y la humana se dan la mano para llevar a cabo una acción conjunta; es éste el itinerario propuesto para la acción humana del cristiano, el cual está llamado a vivir, a imagen del Logos encarnado, en comunión con el sentir de la pro-

": Spengler 1920, 420: *Der anshe Mensch ist ahistonsch, rein gegenwärig (...): er ist „willenlos”. Daruber laße die anluke Schicksalsidec, das Falum. Leinen Zueifel, (...). Folglich kann auch das apollınische Seelenbuld heinen Richtungsfahtor, keinen "Willen" also, enthalten*. Ibid., 545: alst der Mensch ahistorixch wie der Grieche. dessen gesamle Welteindrucke in einer reinen, punktförmigen Gegenwart aufgesaugt werden. so wird das Naturbild slatisch, in jedem einzelnen Augenblick in sich selbst abgexchloasen seins.

1) According to this Chrisuen tradition. Pronoia is not God's looking out in advance to plan the course of history but insead is his interective care for the world, which is quite unlike the business of causing all things to be as they are (unlike Fate or Heimaremene). (Ellior 2015, p. 13). No creo que la actividad del Dios cnsuano escape del concepto de "causalidau". pero juzgo pasitivo el hincapie de Ellion en la interaccoón enure Dios y hombre. 
idencia. Eso sí, no como un esclavo, sino como un hijo verdaderamente dueño de su destino.

\section{BIBLIOGRAFIA.}

E. Anland de Mendieta, Fatalisme et liberté dans l'antiquité Grecque. Amsterdam 1973.

J. J. Ayán Calvo, Antropología de san Justino. Exégesis del mártir a Gen. I-III. Santiago de Compostela/Córdoba 1988.

S.P. Bergjan, Der firsorgende Gott. Der Begriff der MPONOIA Gottes in der apologetischen Literatur der Alten Kirche. Berlin-New York 2002.

1.Daniélou, Histoire des doctrines chrétientes avant Nicée. Paris 1991.

J. Daniélou, Mensaje evangélico y cullura helenística: siglos II y III. Madrid 2002.

H. Diels, Doxographi Graeci. Berolini 1879.

M. W. Elliol, Providence Perceived. Divine Action from a Human Point of View. Berlin-Boston 2015.

S. Fazzo, "La dottrina della provvidenza in Alessandro di Afrodisia", en: S. Fazzo (ed.) Alessandro di Afrodisia, La provvidenza. Questioni sulla provvidenza, Milano 1999, 5-75.

V. L. Félix, "Inmortalidad del alma y escatología en Justino", en M. Alesso, R. Miranda (eds.), Actas del II Simposio Internacional Helenismo Cristianismo, Buenos Aires 2010, 1-9.

V.L. Félix, "La recepción del platonismo en la teología de Justino mártir", Studium. Filosofía y Teologia 31, 2013, 85-96.

A.J. Festugière, L'idéal religieux des grecs el l'évangile, Paris 1981.

M. Frede, A Free Will. Origins of the Notion in Ancient Thought, Berkeley 2011.

M. Friedlinder, Moses Maimonides. The Guide for the Perplexed, Skokie 2002.

Ch. Genequand, Alexander of Aphrodisias on the Cosmos, Leiden-Boston-Köln 2001.

E. J. Goodspeed, Die ältesten Apologeten, Göttingen 1915.

J. Granados, Los misterios de la vida de Cristo en Justino mártir, Roma 2005.

N. Hyldahl, Philosophie und Christentum. Eine Imerpretation der Einleinng zum Dialog Justins, Kopenhagen 1966.

R. Joly, Christianisme el philosophie. Études sur Justin et les Apologistes grecs du deuxième siecle, Bruxelles 1973.

G. Karamanolis, The Philosophy of Early Chrissianity, Bristol 2013.

A. Magris, L'idea del destino nel pensiero amico, Udine 1985.

A. Magris, Destino, provvidenza, predestinazione, Brescia 2008.

P. Merlo, Liberi per vivere secondo il Logos. Principi e criteri dell'agire morale in San Giustino filosofo e martire, Roma 1995.

D. Ruiz Bueno, Padres apostólicos y apologistas griegos, Madrid 2002.

H.-J. Ruland, Die arabischen Fassungen von zwei Schrifien des Alexander von Aphrodisias: Uber die Vorsehung und Über das liberum arbitrium, Saarbrücken 1976.

L. Scheffczyk, Creación y Providencia, Vol. 2.2a. Historia de los Dogmas, Madrid 1974.

R. W. Sharples, "Nemesius of Emesa and Some Theories of Divine Providence", Vigiliae christianae 37, 1983a,141-156.

R. W. Sharples, "Introduction", en: Alexander of Aphrodisias, On Fate, 3-32, London 1983b.

H.-D. Simonin, "La providence selon les pères grecs", en: Dictionnaire de Théologie Catholique, vol. 13, col. 941-960, Paris 1936.

Sociedad biblica de Jerusalén (ed.), Biblia de Jerusalén, Bilbao 2000.

O. Spengler, Der Untergang des Abendlandes, München 1920. 
Th. L. Thompson - Ph. Wajdenbaum (eds.), The Bible and Hellenism: Greek Influence on Jewish and Early Christian Literature, Durham 2014.

D. Torrijos-Castrillejo, "El conocimiento natural de Dios según san Pablo", en: M. López Salva - I. Sanz Extremeño - P. de Paz Amérigo (eds.), Los origenes del cristianismo en la filosofia, la literatura y el arte I. Unos piden señales, otros piden sabiduría, Madrid 2016, 181200.

H. A. Wolfson, Philo. Foundations of Religious Philosophy in Judaism, Christianity, and Islam, Cambridge-Massachusetts 1962. 